\title{
Predicting the Interactome of Xanthomonas oryzae pathovar oryzae for target selection and DB service
} Jeong-Gu Kim ${ }^{\dagger 1}$, Daeui Park ${ }^{\dagger 2}$, Byoung-Chul Kim², Seong-Woong Cho², Yeong Tae Kim ${ }^{1}$, Young-Jin Park ${ }^{1}$, Hee Jung Cho' ${ }^{1}$, Hyunseok Park ${ }^{3}$, KiBong Kim ${ }^{4}$, Kyong-Oh Yoon ${ }^{5}$, Soo-Jun Park ${ }^{6}$, Byoung-Moo Lee*1 and Jong Bhak*2

\begin{abstract}
Address: ${ }^{1}$ Microbial Genetics Division, National Institute of Agricultural Biotechnology (NIAB), Rural Development Administration (RDA), Suwon 441-707, Korea, ${ }^{2}$ Korean BioInformation Center (KOBIC), KRIBB, Daejeon 305-806, Korea, ${ }^{3}$ Department of Computer Science and Engineering, Ewha Womans University, Seoul 120-750, Korea, ${ }^{4}$ Department of Biotechnology and Informatics, Sang Myung University, Cheonan 330-720, Korea, ${ }^{5}$ Macrogen Inc., Seoul 153-781, Korea and ${ }^{6}$ Bioinformatics Team, Electronics and Telecommunications Research Institute (ETRI), Daejeon 305-350, Korea

Email: Jeong-Gu Kim - jkim5aug@yahoo.com; Daeui Park - daeui@kribb.re.kr; Byoung-Chul Kim - bckim@kribb.re.kr; SeongWoong Cho - sucho@kribb.re.kr; Yeong Tae Kim - ytkim33@rda.go.kr; Young-Jin Park - jiny5462@rda.go.kr; Hee Jung Cho - chohj@rda.go.kr; Hyunseok Park - neo@ewha.ac.kr; Ki-Bong Kim - kbkim@smu.ac.kr; Kyong-Oh Yoon - yoonko@macrogen.com; Soo-Jun Park - psj@etri.re.kr; Byoung-Moo Lee* - lbmoo@rda.go.kr; Jong Bhak* - j@bio.cc

* Corresponding authors †Equal contributors
\end{abstract}

Published: 24 January 2008

BMC Bioinformatics 2008, 9:4| doi:|0.||86/|47|-2105-9-4|
Received: 18 July 2007

Accepted: 24 January 2008

This article is available from: http://www.biomedcentral.com/I47|-2 105/9/4 I

(C) $2008 \mathrm{Kim}$ et al; licensee BioMed Central Ltd.

This is an Open Access article distributed under the terms of the Creative Commons Attribution License (http://creativecommons.org/licenses/by/2.0), which permits unrestricted use, distribution, and reproduction in any medium, provided the original work is properly cited.

\begin{abstract}
Background: Protein-protein interactions (PPIs) play key roles in various cellular functions. In addition, some critical inter-species interactions such as host-pathogen interactions and pathogenicity occur through PPIs. Phytopathogenic bacteria infect hosts through attachment to host tissue, enzyme secretion, exopolysaccharides production, toxins release, iron acquisition, and effector proteins secretion. Many such mechanisms involve some kind of protein-protein interaction in hosts. Our first aim was to predict the whole protein interaction pairs (interactome) of Xanthomonas oryzae pathovar oryzae (Xoo) that is an important pathogenic bacterium that causes bacterial blight (BB) in rice. We developed a detection protocol to find possibly interacting proteins in its host using whole genome PPI prediction algorithms. The second aim was to build a DB server and a bioinformatic procedure for finding target proteins in Xoo for developing pesticides that block host-pathogen protein interactions within critical biochemical pathways.
\end{abstract}

Description: A PPI network in Xoo proteome was predicted by bioinformatics algorithms: PSIMAP, PEIMAP, and iPfam. We present the resultant species specific interaction network and host-pathogen interaction, XooNET. It is a comprehensive predicted initial PPI data for Xoo. XooNET can be used by experimentalists to pick up protein targets for blocking pathological interactions. XooNET uses most of the major types of PPI algorithms. They are: I) Protein Structural Interactome MAP (PSIMAP), a method using structural domain of SCOP, 2) Protein Experimental Interactome MAP (PEIMAP), a common method using public resources of experimental protein interaction information such as HPRD, BIND, DIP, MINT, IntAct, and BioGrid, and 3) Domain-domain interactions, a method using Pfam domains such as iPfam. Additionally, XooNET provides information on network properties of the Xoo interactome. 


\begin{abstract}
Conclusion: XooNET is an open and free public database server for protein interaction information for Xoo. It contains 4,538 proteins and 26,932 possible interactions consisting of I8,503 (PSIMAP), 3,II8 (PEIMAP), and 8,938 (iPfam) pairs. In addition, XooNET provides 3,407 possible interaction pairs between two sets of proteins; 141 Xoo proteins that are predicted as membrane proteins and rice proteomes. The resultant interacting partners of a query protein can be easily retrieved by users as well as the interaction networks in graphical web interfaces. XooNET is freely available from http://bioportal.kobic.kr/XooNET/.
\end{abstract}

\section{Background}

Proteins constitute 50 percent or more of the dry weight of living organisms. They have the most diverse biological roles. They function by interacting with other molecules including proteins themselves. Usually, protein-protein interactions are the key mechanisms of normal and pathological functions of living cells. Recently, genomic-scale identification of PPI in model organisms such as Saccharomyces cerevisiae [1-3] and Escherichia coli [4] have been reported to map the network protein-protein interactions. However, few have been known for phytopathogens and their molecular interactions with hosts. Generally, a phytopathogenic bacterium invades hosts in the following steps: attachment to the host tissue, secretion of degradation enzymes, production of exopolysaccharides, release of toxins, acquisition of iron, and secretion of effector proteins [5]. The gene-for-gene theory that PPI between an effector protein from pathogen and the specific receptor in plant host results in the hypersensitive response and resistance was proposed by Flor [6]. Rossier et al. [7] proposed a model for the role of Xanthomonas campestris pv. vesicatoria Hrp proteins in type III secretion and interaction with its plant hosts. Later, Alegria et al. [8,9] proved that the PPI is critical in Hrp type III and type IV secretion systems of Xanthomonas axonopodis pv. citri by yeast twohybrid experiments. There are a few reports on the PPIs involving the effector protein AvrBs3 of Xanthomonas campestris pv. vesicatoria $[10,11]$.

Rice (Oryza sativa) is one of the major crops in the world, and bacterial blight (BB) causes a huge yield loss (as high as $50 \%$ in severely infested fields [12]). Xoo, the rice pathogen causing BB has been completely sequenced [GenBank: AE013598] [13] and the first report on Xoo PPI by glutathione-bead binding experiments. The study included PPIs of several Hrp proteins [14].

Although there was a report showing that some Xoo insertion mutants of unknown or hypothetical protein genes had shown changed pathogenicity [15], it is a long way to go to find all the proteins and their interactions involved in Xoo's pathogenicity. Also, it is expensive and time-consuming to carry out interaction experiments for the whole organism. This led us to develop XooNET which gives us a guidance in targeting pathogenic proteins and their interactions.

In XooNET, predicted PPI information involving Hrp proteins can give us additional function information. For example, Xa21, the resistance gene of rice, has been reported [16]. However, its corresponding Avr protein is yet to be reported. For this instance, the predicted PPI of Xoo can lead users to the function of the effector proteins and finally the target Avr protein(s). There are some pesticides being registered and used against Xoo. However, they were not developed for specific targets, and hence not very effective. The PPI network information Xoo can help the researchers to detect more specific drug targets and increase the pesticide potency.

\section{Construction and Content PSIMAP-based interactions}

4,538 proteins of Xoo were retrieved from NCBI and were aligned with SCOP [17] domains using the PSI-BLAST [18] algorithm with a common expect value (E-value) cutoff of 0.001 [19]. By applying SCOP domain interaction pairs obtained from the PSIMAP [20] based interaction information database, PSIbase [21], 18,503 predicted PPIs were obtained for 1,862 Xoo proteins. This was around $41 \%$ of the total Xoo proteins.

\section{PEIMAP-based interactions}

The same 4,538 proteins of Xoo were aligned with proteins in PEIMAP using the BLASTP [18] algorithm with a cut-off of $40 \%$ sequence identity and $80 \%$ length coverage. The PEIMAP includes PPI information from six popular source databases: DIP (Database of Interacting Proteins) [22], BIND (Biomolecular Interaction Network Database) [23], IntAct (Database system and analysis tools for protein interaction data) [24], MINT (Molecular Interactions Database) [25], HPRD (Human Protein Reference Database) [26], and BioGrid (A general repository for interaction datasets) [27]. By applying PEIMAP interaction pairs, 3,118 predicted PPIs were obtained for 629 Xoo proteins. These PPIs was around $14 \%$ of the total Xoo proteins. 


\section{Calculating Interactions based on iPfam}

Pfam [28] domains of all the Xoo proteins were aligned with hmmpfam by the cut-off of 0.01 (E-value). By integrating them with Pfam domain interaction pairs from iPfam [29], 8,938 predicted protein-protein interactions were constructed with 1,362 selected proteins comprising approximately $30 \%$ of Xoo proteins.

\section{Selecting High-confidence interactions}

As a filter, we used the 'combined score' between any pair of proteins which were predicted by PEIMAP, PSIMAP, and iPfam algorithms. As a result, we selected 684 Xoo proteins participating in 2,494 high-confidence PPIs (> 0.6) that were commonly found in all the three databases encompassing PSIMAP, PEIMAP, and iPfam. Those were further rescaled into the confidence range from 0.0 to 1.0 combining all the scores (these were visualized in the Java applet viewer of a modified Integrator program).

\section{Predicting PPIs between Xoo and Rice}

Oryza sativa is known as the sole host of Xoo. Therefore, we added 3,407 PPI interaction predictions between Xoo and rice (Oryza sativa japonica and Oryza sativa indica). We chose 354 proteins expected to be membrane proteins and extra cellular proteins in Xoo using GO-Slim [30]. With these data and PSIMAP, PEIMAP, and iPfam algorithms, we predicted interactions between Xoo and Oryza sativa japonica $(1,269 / 26,887)$, or Oryza sativa indica (18/ $118)$. As a result, we predicted that 141 Xoo proteins have 3,407 interaction pairs with rice (PEIMAP:25; PSIMAP:2,266; iPfam:2,124). We evaluated many different thresholds of psi-Blast and hmmpfam for domain assignment, and the most adequate one was $10 \mathrm{e}-4$ for PSIMAP, $40 \%$ identity and $70 \%$ coverage for PEIMAP, and $10 e-2$ for iPfam.

\section{Utility}

XooNET can be accessed by gene symbols, gene descriptions, locus tags, and NCBI gi numbers to find gene information and interacting partners not only of Xoo but also of Oryza sativa. Users can also input amino acid sequences. In addition to giving users the functional category of gene sets, XooNET provides the tree of gene ontology annotation using GO-Slim. Figure 1 shows the search interface and the result.

\section{Discussion}

The public interaction databases such as BIND and DIP at this time are limited for the PPIs of Xoo. Therefore, PEI$\mathrm{MAP}$, which is an integrated resource of experimental PPI data, covers only about $14 \%$ of the total Xoo proteins. We found that some PPI pairs reported in experiments (Jang et al., 2007; Kim et al., unpublished) were not predicted by XooNET by using the updated PEIMAP algorithm. The cases include: interactions between HrpB1 and RecA,
HrpB2 and RecA, HrpB5 and XorII, Hpa2 and RecA; AvrBs 2 and HpaP, and AvrBs2 and HrcQ. This shows that the prediction capability of XooNET is still limited for newly discovered protein interactions. By contrast, XooNET predicted that AvrBs2 is interacts with itself. However, a yeast two-hybrid assay showed no self interaction (Kim et al., unpublished). Thus, to increase the prediction boundary of XooNET, we expanded it by providing a field for users to add newly confirmed experimental interaction information.

Avr proteins are known to be crucial effectors that make many bacterial species pathogenic. We found 15 annotated AvrBs3 homologues in Xoo that fall on to three groups according to the interaction promiscuity in protein protein interaction: group 1, zero or one; group 2, more than 60; and group 3, around 10 partners. The highly interactive protein group showed that their numerous partners are functionally related to pathogenicity and can be subdivided. This shows that PPI analysis can assist researchers in discovering new targets and in designing more systematic experiments. One such highly interacting protein, Xoo1125, a hypothetical protein which has over 60 interaction partners including the Avr proteins, caused the loss of pathogenicity when transposon insertion mutation was carried out in a separate experiment. This suggests that XooNET approach is useful in investigating the functions of unknown or hypothetical proteins in Xanthomonas oryzae pathovar oryzae.

\section{Conclusion}

XooNET is an integrated database of mutually complementary protein-protein interaction databases: PSIMAP, PEIMAP, and iPfam. The XooNET server is the first specialized Xoo PPI database which provides information of possibly interacting partners against query proteins. In particular, as only one third of the Xoo proteome are fully annotated, there are still many hypothetical and unknown proteins. XooNET provides a platform for biologists to annotate them by predicting their interaction partners and looking into their pathways.

\section{Methods \\ PSIMAP Algorithm}

The basic procedure of PSIMAP is to infer interactions between proteins by using their homologs. Interactions among domains or proteins for known PDB (Protein Data Bank) structures are the basis for the prediction. If an unknown protein has a homolog to a domain, PSIMAP assumes that the query tends to interact with its homolog's partners. Its concept is called 'homologous interaction'. The original interaction between two proteins or domains is based on the euclidean distance. Therefore, PSIMAP gives a structure based interaction prediction [20]. 
(a)

XOO NET Integrated protein-protein interaction database of

Xanthomonas oryzae pathovar oryzae KACC10331

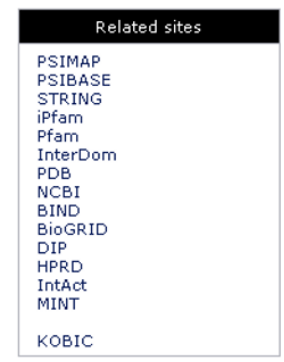

Home

Help

Download data

Statistics

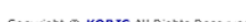

(b)

Sorted by peimap $\vee$ sort
Query : AAW74575.1 (58425538) - ffh - signal recognition particle protein ENcal

Xanthomonas oryzae pv. oryzae KACC10331 vS Xanthomonas oryzae pv. oryzae KACC10331.

\begin{tabular}{|c|c|c|c|c|c|c|c|c|c|c|c|c|}
\hline \multirow{2}{*}{\multicolumn{2}{|c|}{$\begin{array}{c}\text { Accession ID } \\
{[\nabla \Delta]}\end{array}$}} & \multirow{2}{*}{$\begin{array}{c}\text { Gene Symbol } \\
{[\nabla \Delta]}\end{array}$} & \multirow{2}{*}{$\begin{array}{c}\text { Locus Tag } \\
{\left[\nabla_{\Delta}\right]}\end{array}$} & \multicolumn{2}{|c|}{ Experiment } & \multicolumn{3}{|c|}{ Prediction } & \multirow{2}{*}{$\begin{array}{c}\text { Confidence } \\
\text { Score } \\
{[\nabla \Delta]}\end{array}$} & \multirow{2}{*}{$\begin{array}{l}\text { Description } \\
{[\nabla \Delta]}\end{array}$} & \multirow{2}{*}{$\begin{array}{c}\text { SCOP Domain } \\
{[\nabla \Delta]}\end{array}$} & \multirow{2}{*}{$\begin{array}{l}\text { GI Number } \\
{\left[\nabla_{\Delta}\right]}\end{array}$} \\
\hline & & & & $\begin{array}{c}\text { peimap } \\
{[\nabla \Delta]}\end{array}$ & $\begin{array}{l}\text { user insert } \\
{[\nabla \Delta]}\end{array}$ & $\begin{array}{c}\text { psimap } \\
{[\nabla \Delta]}\end{array}$ & $\begin{array}{l}\text { ipfam } \\
{[\nabla \Delta]}\end{array}$ & $\begin{array}{c}\text { interdom } \\
{\left[\nabla_{\Delta}\right]}\end{array}$ & & & & \\
\hline 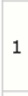 & AAW74575.1 & $\mathrm{ffh}$ & xoo1321 & $\underline{2}$ & - & 1.28 & $\underline{55.15}$ & $\underline{31.92}$ & - & signal recognition particle protein & $\begin{array}{l}\frac{a .24 .13 .1}{c .37 .1 .10} \\
\underline{a .36 .1 .1}\end{array}$ & $\underline{58425538}$ \\
\hline ? & AAW74289.1 & Ion & x001035 & $\underline{1}$ & - & - & - & - & 0.27 & ATP-dependent serine proteinase La & $\begin{array}{l}\text { c. } 37.1 .20 \\
\text { d.14.1.10 }\end{array}$ & $\underline{58425252}$ \\
\hline 3 & A.AW74016.1 & fabs & x000762 & $\underline{1}$ & - & - & - & - & 0.27 & beta-hydroxydecanoyl-ACP dehydratase & d.38.1.2 & $\underline{58424979}$ \\
\hline 4 & AAW74874.1 & rplu & x001620 & $\underline{1}$ & - & - & - & - & 0.27 & $50 S$ ribosomal protein $\mathrm{L} 21$ & - & $\underline{58425837}$ \\
\hline 5 & A.W 74875.1 & rpma & X001621 & $\underline{1}$ & - & - & - & - & 0.27 & $50 S$ ribosomal protein L27 & b.84.4.1 & $\underline{58425838}$ \\
\hline 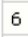 & A.AW75220.1 & fabz & x001966 & $\underline{1}$ & - & - & - & - & 0.27 & (3r)-hydroxymyristoyl ACP dehydrase & d. 38.1 .6 & $\underline{58426183}$ \\
\hline 7 & AAW75660.1 & gyra & $x 002406$ & $\underline{1}$ & - & - & - & - & 0.27 & DNA gyrase subunit $A$ & - & $\underline{58426623}$ \\
\hline
\end{tabular}

Figure I

XooNET system and interfaces. (a) XooNET integrates four complementary protein-protein interaction databases including PSIMAP, PEIMAP, and iPfam. It shows three search interfaces: (I) search in high-confidence PPI network, (2) keyword and sequence search, and (3) functionally categorized tree navigation of gene ontology annotation. (b) A search result showing the list of predicted interacting proteins, supporting databases, and their synonymous IDs.
XOONET is a specialized Xanthomonas sp. protein-protein interaction database. It shows feasible domain-domain interactions of Xanthomonas sp.. Additionally, XooNET provides gene interfaces.

1. PPI NETWORK : High-confidence protein-protein interactions dynamically visualized in a Java applet viewe

2. Quick search

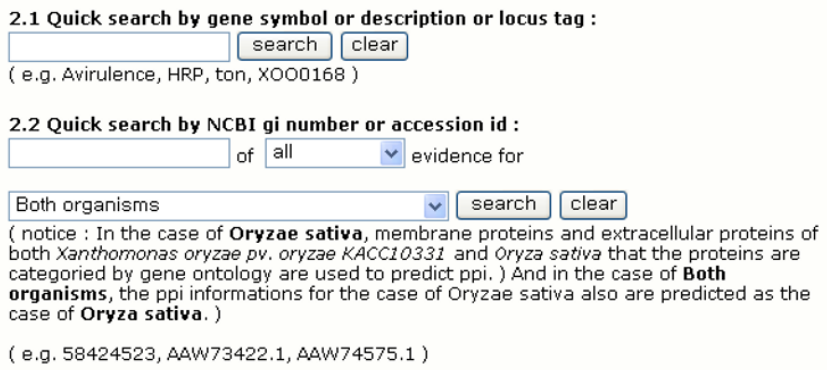

3. Search by Sequence : move to sequence search page

4. Functionally categorized tree navigation

(Gene Ontology Annotation ( GO Slim, 04-OCT-2007)

+ biological process ( 1783 )

+ cellular_component ( 618 )

† molecular_function ( 1843 ) 


\section{PEIMAP Algorithm}

PEIMAP (Protein Experimental Interactome MAP) has been constructed by combining several experimental protein-protein interaction databases. We carried out redundancy check to remove identical protein sequences from the source interaction databases. At present, it contains 116,773 proteins and 229,799 interactions.

\section{Authors' contributions}

JGK started this project, wrote the manuscript, manually validated the interaction lists and tested part of the interaction with yeast two-hybrid system. DP designed the system and wrote the manuscript. BCK constructed the database. SWC developed the website. YTK, YJP and HJC manually validated the web, and performed pathogenicity tests for the Xoo insertion mutants including Xoo1125. HP and KBK constructed automatic graph building modules. KOY and SJP developed pre-search basic modules, gene ontology mapping. BML directed the study. JB conceived and directed the study and helped to draft the manuscript.

\section{Acknowledgements}

We thank our colleagues at KOBIC, especially, Woo-yeon Kim and SungHun Lee. This project was supported by a grant from the KRIBB Research Initiative Program of Korea and ROI-2004-000-10172-0 grant of KOSEF, by the grant from the NIAB 05-4-I2-4-2 and by NIAB 07-4-2I-22-I

(BioGreen2I 20070501034003 from RDA).

\section{References}

I. Uetz P, Giot L, Cagney G, Mansfield TA, Judson RS, Knight JR, Lockshon D, Narayan V, Srinivasan M, Pochart P, Qureshi-Emili A, Li Y, Godwin B, Conover D, Kalbfleisch T, Vijayadamodar G, Yang M, Johnston M, Fields S, Rothberg JM: A comprehensive analysis of protein-protein interactions in Saccharomyces cerevisiae. Nature 2000, 403(6770):623-627.

2. Ito T, Tashiro K, Muta S, Ozawa R, Chiba T, Nishizawa M, Yamamoto $\mathrm{K}$, Kuhara S, Sakaki Y: Toward a protein-protein interaction map of the budding yeast: A comprehensive system to examine two-hybrid interactions in all possible combinations between the yeast proteins. Proc Natl Acad Sci USA 2000, 97(3): II43-II47.

3. Ito T, Chiba T, Ozawa R, Yoshida M, Hattori M, Sakaki Y: A comprehensive two-hybrid analysis to explore the yeast protein interactome. Proc Natl Acad Sci USA 200I, 98(8):4569-4574

4. Arifuzzaman M, Maeda M, Itoh A, Nishikata K, Takita C, Saito R, Ara T, Nakahigashi K, Huang HC, Hirai A, Tsuzuki K, Nakamura S, AltafUl-Amin M, Oshima T, Baba T, Yamamoto N, Kawamura T, lokaNakamichi T, Kitagawa M, Tomita M, Kanaya S, Wada C, Mori H: Large-scale identification of protein-protein interaction of Escherichia coli K-I2. Genome Res 2006, 16(5):686-69I.

5. Boucher $C$, Genin S, Arlat M: Concepts actuels sur la pathogénie chez les bactéries phytopathogènes. CR Acad Sci III 200I, 324(10):915-922.

6. Flor $\mathrm{HH}$ : Current status of the gene-for-gene concept. Annu Rev Phytopathol 1971, 9:275-296.

7. Rossier O, Van den Ackerveken G, Bonas U: HrpB2 and HrpF from Xanthomonas are type III-secreted proteins and essential for pathogenicity and recognition by the host plant. Mol Microbiol 2000, 38(4):828-838.

8. Alegria MC, Docena C, Khater L, Ramos CH, da Silva AC, Farah CS: New protein-protein interactions identified for the regulatory and structural components and substrates of the type III Secretion system of the phytopathogen Xanthomonas axonopodis Pathovar citri. J Bacteriol 2004, I 86(18):6186-6I97.
9. Alegria MC, Souza DP, Andrade MO, Docena C, Khater L, Ramos $\mathrm{CH}$, da Silva AC, Farah CS: Identification of new protein-protein interactions involving the products of the chromosome- and plasmid-encoded type IV secretion loci of the phytopathogen Xanthomonas axonopodis pv. citri. J Bacteriol 2005, |87(7):2315-2325.

10. Büttner D, Lorenz C, Weber E, Bonas U: Targeting of two effector protein classes to the type III secretion system by a $\mathrm{HpaC}$ - and $\mathrm{HpaB}$-dependent protein complex from Xanthomonas campestris pv. vesicatoria. Mol Microbiol 2006, 59(2):5।3-527.

II. Gurlebeck D, Szurek B, Bonas U: Dimerization of the bacterial effector protein AvrBs3 in the plant cell cytoplasm prior to nuclear import. Plant J 2005, 42(2): $175-187$.

12. Ezuka A, Kaku H: A historical review of bacterial blight of rice. Bull Natl Inst Agrobiol Resour (Japan) 2000, 15:53-54.

13. Lee BM, Park YJ, Park DS, Kang HW, Kim JG, Song ES, Park IC, Yoon UH, Hahn JH, Koo BS, Lee GB, Kim H, Park HS, Yoon KO, Kim JH, Jung $\mathrm{CH}$, Koh NH, Seo JS, Go SJ: The genome sequence of Xanthomonas oryzae pathovar oryzae KACCI 0331 the bacterial blight pathogen of rice. Nucleic Acids Res 2005, 33(2):577-586.

14. Jang M, Park BC, Lee DH, Bae K-H, Cho S, Park HS, Lee BR, Park SG: Interaction proteome analysis of Xanthomonas Hrp proteins. J Microbiol Biotechnol 2007, 17:359-363.

15. Lee BM, Park YJ, Kim JG, Kang HW: Genomic study of Xanthomonas oryzae pv. oryzae KACCI033I. Proceedings of the International Workshop Xanthomonas genome research: 27-28 October 2005; Bielefeld Germany .

16. Song WY, Wang GL, Chen LL, Kim HS, Pi LY, Holsten T, Gardner J, Wang B, Zhai WX, Zhu LH, Fauquet C, Ronald P: A receptor kinase-like protein encoded by the rice disease resistance gene, Xa2 I. Science 1995, 270(5243): I804-1806.

17. Hubbard TJ, Murzin AG, Brenner SE, Chothia C: SCOP: a structural classification of proteins database. Nucleic acids research 1997, 25(I):236-239.

18. Altschul SF, Madden TL, Schaffer AA, Zhang J, Zhang Z, Miller W, Lipman DJ: Gapped BLAST and PSI-BLAST: a new generation of protein database search programs. Nucleic acids research 1997, 25(I7):3389-3402.

19. Park D, Lee S, Bolser D, Schroeder M, Lappe M, Oh D, Bhak J: Comparative interactomics analysis of protein family interaction networks using PSIMAP (protein structural interactome map). Bioinformatics (Oxford, England) 2005, 2 I (I5):3234-3240.

20. Park J, Lappe $M$, Teichmann SA: Mapping protein family interactions: intramolecular and intermolecular protein family interaction repertoires in the PDB and yeast. Journal of molecular biology 200I, 307(3):929-938.

2I. Gong S, Yoon G, Jang I, Bolser D, Dafas P, Schroeder M, Choi H, Cho Y, Han K, Lee S, Choi H, Lappe M, Holm L, Kim S, Oh D, Bhak J: PSIbase: a database of Protein Structural Interactome map (PSIMAP). Bioinformatics (Oxford, England) 2005, 2 I (10):254I-2543.

22. Xenarios I, Rice DW, Salwinski L, Baron MK, Marcotte EM, Eisenberg $\mathrm{D}$ : DIP: the database of interacting proteins. Nucleic acids research 2000, 28(I):289-29I.

23. Bader GD, Hogue CW: BIND - a data specification for storing and describing biomolecular interactions, molecular complexes and pathways. Bioinformatics (Oxford, England) 2000, 16(5):465-477.

24. Hermjakob H, Montecchi-Palazzi L, Lewington C, Mudali S, Kerrien S, Orchard S, Vingron M, Roechert B, Roepstorff P, Valencia A, Margalit $H$, Armstrong J, Bairoch A, Cesareni G, Sherman D, Apweiler R: IntAct: an open source molecular interaction database. Nucleic acids research 2004:D452-455.

25. Zanzoni A, Montecchi-Palazzi L, Quondam M, Ausiello G, HelmerCitterich M, Cesareni G: MINT: a Molecular INTeraction database. FEBS letters 2002, 5 I 3(1): $135-140$.

26. Peri $S$, Navarro JD, Kristiansen TZ, Amanchy R, Surendranath $V$ Muthusamy B, Gandhi TK, Chandrika KN, Deshpande N, Suresh S, Rashmi BP, Shanker K, Padma N, Niranjan V, Harsha HC, Talreja N, Vrushabendra BM, Ramya MA, Yatish AJ, Joy M, Shivashankar HN, Kavitha MP, Menezes M, Choudhury DR, Ghosh N, Saravana R, Chandran S, Mohan S, Jonnalagadda CK, Prasad CK, Kumar-Sinha C, Deshpande KS, Pandey A: Human protein reference database as a discovery resource for proteomics. Nucleic acids research 2004:D497-50I. 
27. Stark C, Breitkreutz BJ, Reguly T, Boucher L, Breitkreutz A, Tyers M: BioGRID: a general repository for interaction datasets. Nucleic acids research 2006:D535-539.

28. Sonnhammer EL, Eddy SR, Birney E, Bateman A, Durbin R: Pfam: multiple sequence alignments and HMM-profiles of protein domains. Nucleic acids research 1998, 26(I):320-322.

29. Finn RD, Marshall M, Bateman A: iPfam: visualization of proteinprotein interactions in PDB at domain and amino acid resolutions. Bioinformatics (Oxford, England) 2005, 2 I (3):4I0-4I2.

30. Camon E, Magrane M, Barrell D, Lee V, Dimmer E, Maslen J, Binns D, Harte N, Lopez R, Apweiler R: The Gene Ontology Annotation (GOA) Database : sharing knowledge in Uniprot with Gene Ontology. Nucleic Acids Research 2004:D262-D266.

Publish with Bio Med Central and every scientist can read your work free of charge

"BioMed Central will be the most significant development for disseminating the results of biomedical research in our lifetime. "

Sir Paul Nurse, Cancer Research UK

Your research papers will be:

- available free of charge to the entire biomedical community

- peer reviewed and published immediately upon acceptance

- cited in PubMed and archived on PubMed Central

- yours - you keep the copyright

Submit your manuscript here:

http://www.biomedcentral.com/info/publishing_adv.asp 